\title{
Effect of Surface Texturing on Stresses during Rapid Changes in Temperature
}

\author{
Lei Han ${ }^{1,2,3}$, Yunxin $\mathrm{Wu}^{1,2,3, *}$, Hai Gong ${ }^{3}$ and Wenze Shi ${ }^{3}$ \\ 1 Light Alloy Research Institute, Central South University, Changsha 410083, China; leihan.me@outlook.com \\ 2 Nonferrous Metal Oriented Advanced Structural Material and Manufacturing Cooperative Innovation \\ Center, Central South University, Changsha 410083, China \\ 3 State Key Laboratory of High-Performance Complex Manufacturing, Central South University, \\ Changsha 410083, China; ghky001@163.com (H.G.); swzkycsu@163.com (W.S.) \\ * Correspondence: wyxcsu@163.com; Tel.: +86-189-3246-4133
}

Academic Editor: Hugo F. Lopez

Received: 24 September 2016; Accepted: 17 November 2016; Published: 23 November 2016

\begin{abstract}
Recently, there has been great interest in the application of the surface texturing method to enhance material surface performance. Material surfaces sometimes experience rapid temperature changes, and the local surface will obviously generate thermal stresses, which may be detrimental to the material structure. In order to understand the relationship between surface texturing and stresses, a numerical approach is used to investigate the effects of surface texturing on stresses. The results show that surface texturing can generate compressive stresses along the normal direction of the surface, and that strong tensional stresses can be formed in the center of a surface at the same time that are beneficial to material surface performance. However, a smooth surface cannot generate these beneficial stresses. In addition, there is an optimum design size with respect to textures, and the most desirable state of stress in a surface layer can be achieved at this size.
\end{abstract}

Keywords: surface texturing; stresses; modeling

\section{Introduction}

Surface texturing is a well-known approach to improve material surface properties. It is the process of applying a specific type of pattern of roughness to a surface in order to change its properties. Some recent publications [1-8] have mentioned its many roles, such as in the elimination of interface friction and wear, in the enhancement of the lubrication state, for mechanical seals, etc. For example, Shen et al. [9] studied the tribological and sealing performance of a piston ring with a specially-designed textured surface in a diesel engine and found that surface texturing led to a reduction of up to about $15 \%$ in total friction. Usman et al. [10] used a mixed lubrication model and realistic oil rheology to investigate the tribo-characteristics of a partially-textured, barrel-shaped piston ring operating under real engine conditions. Ighil et al. [11] adopted a numerical method to study journal-bearing characteristic modeling for cases of texture presence or absence on bearing surfaces and found that being fully textured can lead to some significant positive effects (up to $+27 \%$ minimum film thickness increase, and up to $-3.4 \%$ friction coefficient reduction). Meng et al. [12] explored the effects of a compound dimple on the tribological performance of journal bearing; the results showed that the compound dimple could supply a larger load-carrying capacity and a lower friction coefficient due to its double hydrodynamic action in comparison with a simple dimple. Therefore, surface texturing processes have these important roles, which render them useful in many fields of modern materials, including metal and alloy materials. 
During flight, aircraft, spacecraft, and other structures sometimes suffer from rapid temperature changes. The stresses distribute on the surface of the material, which can be affected by these abrupt changes.

It is well known that these stresses have a significant effect on the performance of a material. Sometimes they can be both beneficial and detrimental to a component. Useful aspects are always sought, if possible, through the adoption of feasible methods. Knowledge of material modification properties, such as the stress distribution states, is of major importance.

In designing a beneficial stress state or removing a detrimental one, the material performance will be further improved. A number of researchers have reported on these topics, and have attained some notable achievements. Kishimoto et al. [13] adopted an ion-exchange method to induce compressive stresses in the surface layer of ceramics, and found the mechanical strength of $\mathrm{Na} \beta$-alumina ceramics to be enhanced by up to $50 \%$. Wagner et al. [14] used laser peening, shot peening, and ball-burnishing, respectively, to change the state of stresses in materials, and the results showed that all of these methods could generate compressive residual stresses that reinforce surface properties. Other methods, such as thermal tempering and deep rolling, have also been reported by scholars [15-27].

However, the relationship between surface texturing and the stresses in the material surface layer has been rarely reported on, especially the effects of surface texturing on stress distribution in a material surface layer during rapid changes in temperature.

In this paper, a numerical approach is used to study the effects of surface texturing on thermal stresses (which result from rapid changes in temperature). In addition, the numerical results have also been indirectly verified.

\section{Geometry Model}

This study focuses on the relationship between surface texturing and its local thermal stresses, which result from rapid changes in temperature. A detailed flow chart, shown in Figure 1, shows the surface temperature of the examined geometry's rapid change from $770 \mathrm{~K}$ to $290 \mathrm{~K}$; the texturing region and the smooth region generate thermal stresses on the surface layer due to the temperature effect.

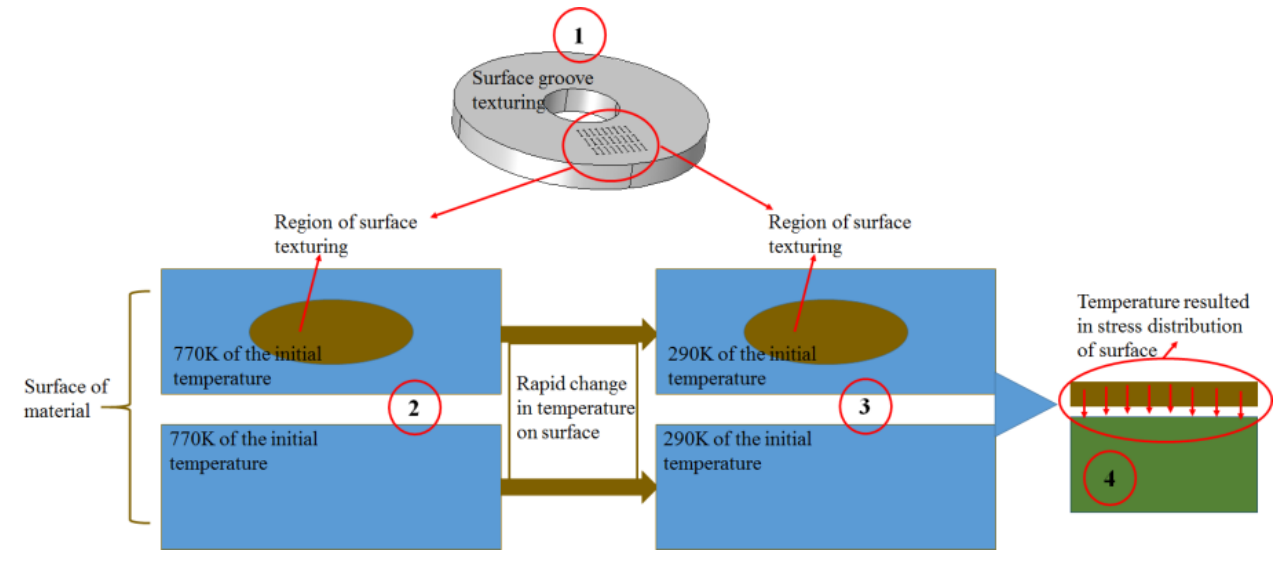

Figure 1. Detail flow chart of thermal stress generation.

As shown in Figure 1, small-scale grooves, which have a regular pattern, are processed on the surface. These grooves can be processed using methods such as laser-texturing, micromachining, etc. [2,5]. Additionally, surface groove texturing has been confirmed to be an effective method in many areas [3]; thus, here, the surface of the material is suggested in order to process a series of regular small-scale grooves. Because of the symmetry and the periodicity of the grooves, one groove unit is selected as a study object and a two-dimensional research model is adopted. The model, after simplification, is shown in Figure 2. 


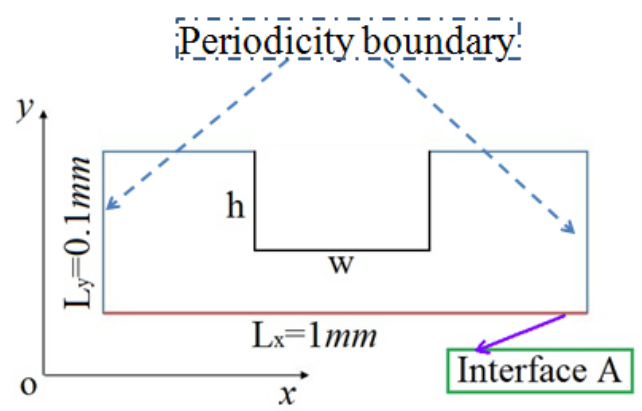

Figure 2. Surface texturing unit model.

\section{Numerical Methods}

\subsection{Basic Governing Equations}

In this study, the stresses in a surface layer are caused by rapid changes in temperature (varying from $770 \mathrm{~K}$ to $290 \mathrm{~K}$ ), and this problem relates to the thermal solid mechanical theory. The governing equations include an equilibrium equation, geometry equation, and constitutive equation. These equations are solved using commercial code ABAQUS, based on the finite element method (FEM). In addition, the relationship between surface texturing and local stresses of surfaces is considered; plastic deformations are not considered, and there are three basic assumptions: solid materials are isotropic, neglect viscosity or rate independence, and have small deformations. Based on these assumptions, the two-dimensional governing equations are noted to be as follows:

Equilibrium equations:

$$
\begin{aligned}
& \frac{\partial \sigma_{x x}}{\partial x}+\frac{\partial \tau_{x y}}{\partial y}=0 \\
& \frac{\partial \tau_{x y}}{\partial x}+\frac{\partial \sigma_{y y}}{\partial y}=0
\end{aligned}
$$

Geometry equations:

$$
\begin{gathered}
\varepsilon_{\mathrm{xx}}=\frac{\partial u}{\partial x} \\
\varepsilon_{\mathrm{yy}}=\frac{\partial v}{\partial y} \\
\gamma_{\mathrm{xy}}=\frac{\partial v}{\partial x}+\frac{\partial u}{\partial y}
\end{gathered}
$$

Constitutive equations:

$$
\begin{gathered}
d \varepsilon_{\mathrm{xx}}=\mathbf{D}_{\mathrm{ep}}^{-1} d \sigma_{\mathrm{xx}}+\alpha \Delta T \\
d \varepsilon_{\mathrm{yy}}=\mathbf{D}_{\mathrm{ep}}^{-1} d \sigma_{\mathrm{yy}}+\alpha \Delta T \\
d \gamma_{\mathrm{xy}}=\mathbf{D}_{\mathrm{ep}}^{-1} d \tau_{\mathrm{xy}}
\end{gathered}
$$

Where $\alpha$ is the expansion coefficient of a material and $\Delta T$ is the temperature drop. $\mathbf{D}_{\text {ep }}$ is termed the elastic-plastic matrix, which is shown as follows:

$$
\mathbf{D}_{\mathrm{ep}}=\mathbf{D}-\mathbf{D}\left(\frac{\partial F}{\partial \sigma}\right)\left(\frac{\partial F}{\partial \sigma}\right)^{T} \mathbf{D}\left[A+\left(\frac{\partial F}{\partial \sigma}\right)^{T} \mathbf{D}\left(\frac{\partial F}{\partial \sigma}\right)\right]^{-1}
$$


where $\mathbf{D}$ is an elastic matrix, which depends on the Young's modulus and the Poisson ratio of a material; $F$ is the Huber-Mises yield function; $\sigma$ represents $\left[\begin{array}{lll}\sigma_{x x} & \sigma_{y y} & \tau_{x y}\end{array}\right]$ of the matrix. Because the solid material is isotropic, neglects viscosity or rate independence, and has small deformations in this study, $\partial \mathrm{F} / \partial \sigma=0$. In other words, $\mathbf{D}_{\mathrm{ep}}=\mathbf{D}$ in the constitutive equations. The elastic matrix $\mathbf{D}$ can be depicted as follows:

$$
\mathbf{D}=\frac{E}{1-\mu^{2}}\left[\begin{array}{ccc}
1 & \mu & 0 \\
\mu & 1 & 0 \\
0 & 0 & \frac{1-\mu}{2}
\end{array}\right]
$$

where $E$ is the Young's modulus of a material and $\mu$ is the Poisson ratio.

\subsection{Definition, Material Parameters and Model Validation}

The small-scale grooves were processed on the surface, and the effect of the groove on local thermal stresses was observed. Thus, the selection of material parameters is not very rigorous, and in this work 7xxx aluminum alloy is considered. The density is defined as $2830 \mathrm{~kg} / \mathrm{m}^{3}$, the Young's modulus is $71,200 \mathrm{MPa}$ at $290 \mathrm{~K}$ and $24,600 \mathrm{MPa}$ at $770 \mathrm{~K}$, the Poisson ratio is 0.33 , and the thermal expansion coefficient is $3.0 \times 10^{-5}$. The other model parameters, which represent the characteristic value size of the groove, are defined as shown in Table 1.

Table 1. Definition of computing parameters.

\begin{tabular}{c}
\hline Texturing Parameters \\
\hline$H=\frac{h}{L_{\mathrm{y}}}=0.1,0.3,0.5,0.7$ \\
$W=\frac{w}{L_{\mathrm{x}}}=0.1,0.3,0.5,0.7$ \\
\hline
\end{tabular}

The commercial code ABAQUS has been extensively applied in order to solve the nonlinear/linear problem of the material, and was confirmed by experiments. Zhou et al. [28] utilized ABAQUS to analyze thermal stresses in sandwich ceramics, and the results are in good agreement with experiments. Fialko et al. [29] have also confirmed that simulations using ABAQUS can be consistent with experimental data. In this work, the mathematical modeling is similar to the examples listed above; therefore, the numerical methods used here are feasible and accurate.

\subsection{Boundary Condition and Mesh Information}

The computation domain is shown in Figure 2. Because this domain is one of many groove units, the two sides of the computation domain were set as a periodic boundary, and interface $A$ was set as the displacement boundary. The initial temperature in the surface layer had a uniform distribution, and the initial temperature was set to $770 \mathrm{~K}$; the final temperature was set to $290 \mathrm{~K}$.

Four structure quad mesh elements were assigned to a common computational model, and the results, based on the four mesh elements, were compared, as shown in Figure 3. To begin with, the results between element sizes of 0.05 and 0.01 have large differences. As the element size decreases, the difference becomes smaller. When the element size is 0.005 , the result does not vary with respect to the element size. Figure 3 shows that the results under element sizes of 0.005 and 0.001 are consistent. As a result, in this study, an element size of 0.005 is used and the domain element number is approximately 12,000 . 


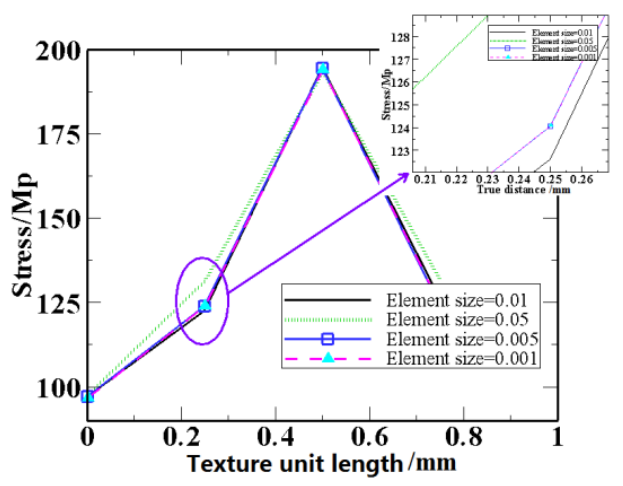

Figure 3. Comparison of computational results of different element sizes.

\section{Results and Discussion}

Simulations of the local thermal stresses of surface texturing were carried out; stresses in smooth surfaces show a uniform distribution compared to surface texturing. This conclusion can be seen in Figure 4. Additionally, Yang et al. [30] obtained a similar conclusion when simulating the quenching process in A357 aluminum alloy.

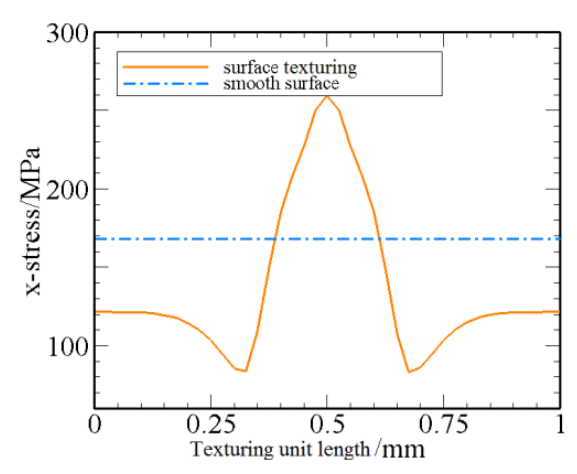

(a)

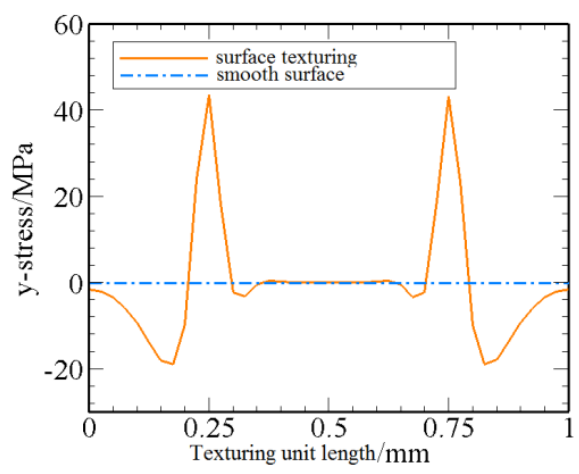

(b)

Figure 4. Stress distributions in interface $A$ : (a) along the $x$ directions; (b) along the $y$ directions.

However, the stresses of surface texturing have significant differences compared to smooth surfaces. Figure 4 shows the distribution of stresses in interface $A$ with surface texturing along the $x$ and $y$ directions. This chart clearly exhibits that surface texturing can cause an asymmetric stress distribution in interface $A$.

\subsection{Effect of Texturing Width on Stress}

Generally, compressive stresses in the surface layer, which occur along the thickness direction ( $y$-direction in this paper), are always expected. However, in the horizontal direction ( $x$-direction), the desirable distribution of stresses has two states: tensional stresses in the center region and compressive stresses in the other region.

Figure 5 shows the stress distribution in interface $A$ along the $y$-direction under different texturing widths; the curves exhibit similar trends at texturing widths of $W=0.1,0.3,0.5$, and 0.7. Though all curves exhibit asymmetry, the levels of asymmetry are different. This means that the stress will generate either a compressive force or an extensional force in interface $A$. When the negative values in the curve have a greater proportion than the positive values, for example, the sum of the stresses in interface $A$ will be a negative value (which represents the compressive force, and will be beneficial to the surface performance); conversely, the tensional force will be obtained. 


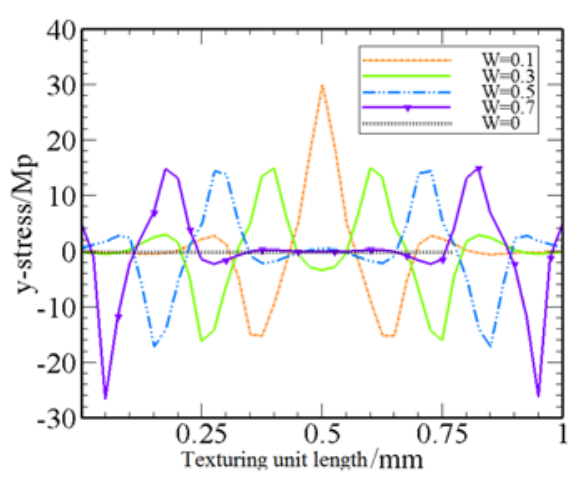

(a)

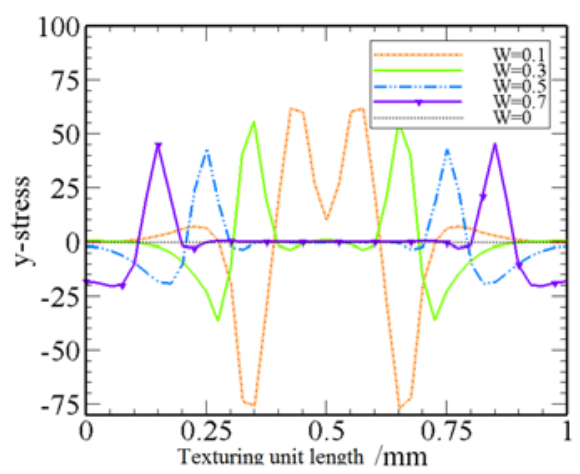

(c)

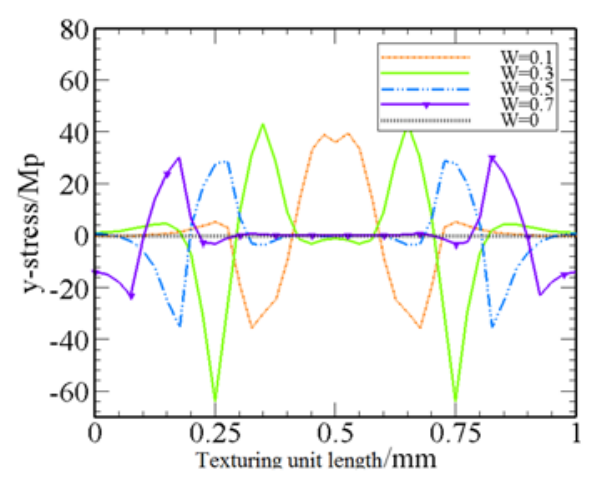

(b)

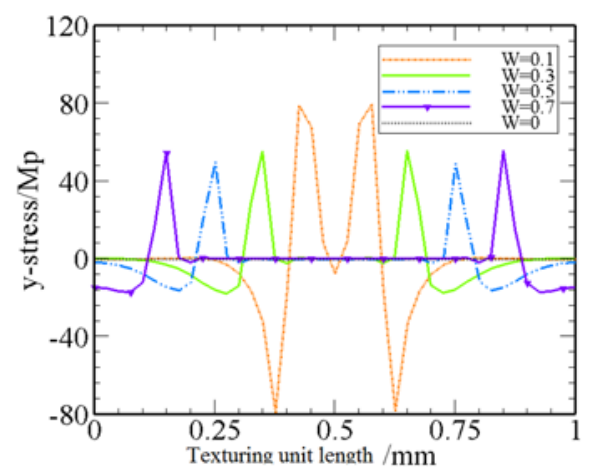

(d)

Figure 5. Distribution of stresses along the $y$ direction at different texturing widths: $(\mathbf{a}) H=0.1 ;(\mathbf{b}) H=$ $0.3 ;$ (c) $H=0.5 ;$ (d) $H=0.7$.

By carefully analyzing the curves in Figure 5 and comparing them with each other, it can be found that interface $A$ was able to increase the compressive force along the thickness direction at certain texturing widths. This is also clearly observed in Figure 6; accordingly, when the texturing depth is $H>0.1$, the curves show a common trend. In other words, the state of the stress changes with the texturing width, from tensional stresses to compressive stresses.

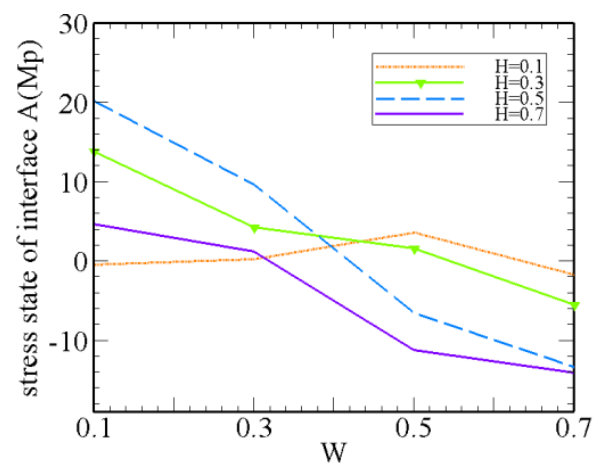

Figure 6. State of stress changes with texturing widths.

Therefore, while material structures sometimes experience rapid temperature changes, surface texturing will automatically generate a state of compressive stress along the thickness of a surface layer. This will add further improvement to the performance of a material. 
The above-mentioned analysis aims to confirm the beneficial effects of surface texturing, such as stress distributions, which occur along the thickness direction of a surface layer. Similarly, the state of the stresses in the horizontal ( $x$-direction) direction also achieves desirable results. Figure 7 shows the distribution of stresses in interface $A$ along the $x$-direction. With respect to the stresses along the $x$-direction, it is always the hope that larger tensional stresses in the center region can be achieved so that the surface fatigue life is enhanced under shear conditions.

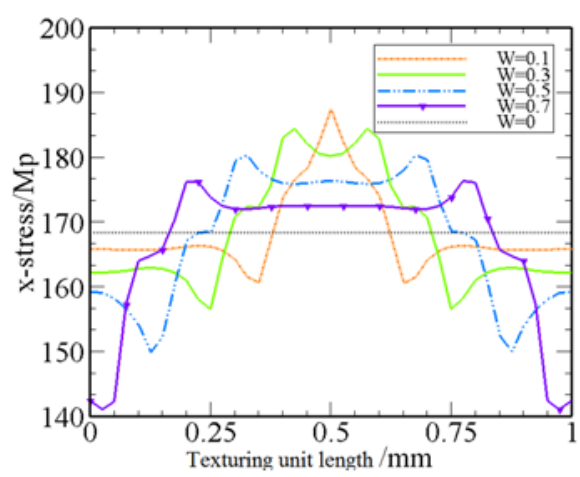

(a)

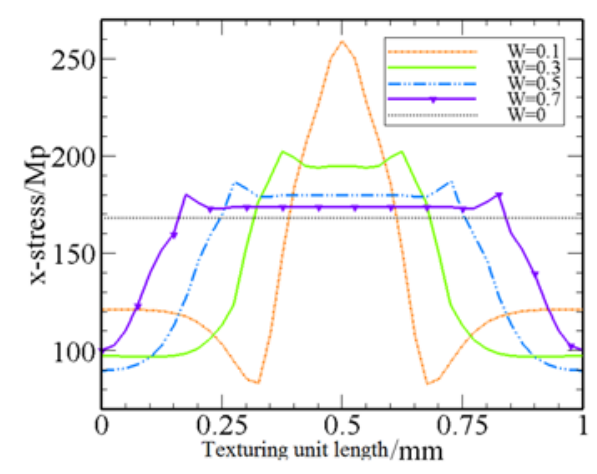

(c)

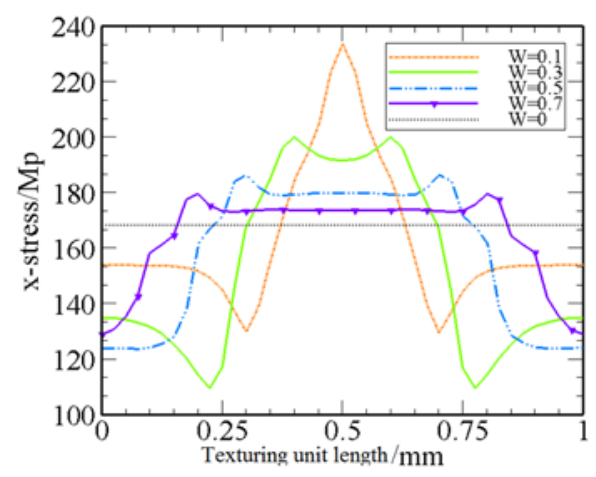

(b)

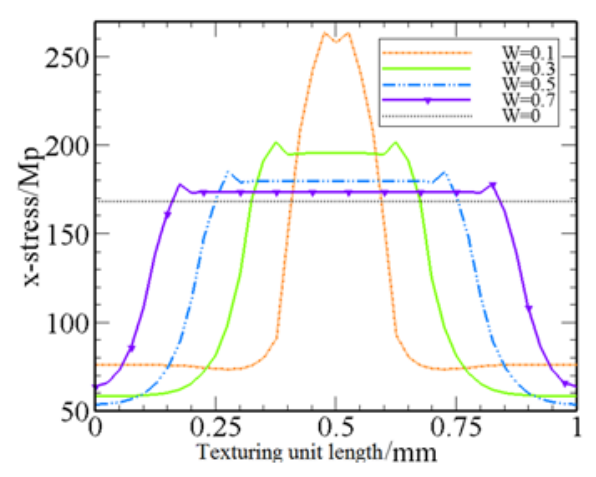

(d)

Figure 7. Distribution of stresses along the $x$-direction with different texturing widths. (a) $H=0.1$; (b) $H=0.3$; (c) $H=0.5$; (d) $H=0.7$.

As can be seen in Figure 7, surface texturing can obviously generate tensional stresses in the center, and the peak value is located at the center of the texturing. When the texturing width is $W=0.1$, the tensional stresses in the center are largest. With an increase in the texturing width, the value of the largest tensional stress is diminished. This means that a small-scale width should be selected in order to pay attention to the $x$-direction stresses.

When considering both $x$-direction stresses and $y$-direction stresses, the texturing width must be cautiously selected, as the stress curve trends of the $y$-direction are almost opposite to those of the $x$-direction. As can be seen in Figure 6, compressive stresses will be large as the texturing width increases; in view of this, a compromise must be implemented. By carefully comparing Figures 6 and 7 , the texturing width of $W=0.5$ may be the optimal design size. If we only consider the $y$-direction, the optimum is $W=0.7$, and the optimum should be selected as $W=0.1$ when only the $x$-direction is considered. 


\subsection{Effect of Texturing Depth on Stresses}

Similarly, the texturing depth had a significant effect on the stresses. If a depth existed at an optimum value, the unique design scale of the texturing could be determined. The above-mentioned analysis has obtained the optimum texturing width under three conditions. When only the $y$-direction is considered, the optimum texturing width is $W=0.7$.

Figure 8 shows the effect of different texturing depths on stresses in interface $A$ along the $y$-direction when $W=0.7$. With an increase of the texturing depth, the domain of the compressive stresses gradually increases, which means that the largest compressive force will be achieved at $H=0.7$. This can be also clearly observed in Figure 9, where the compressive force is stronger with the boost in the texturing depth.

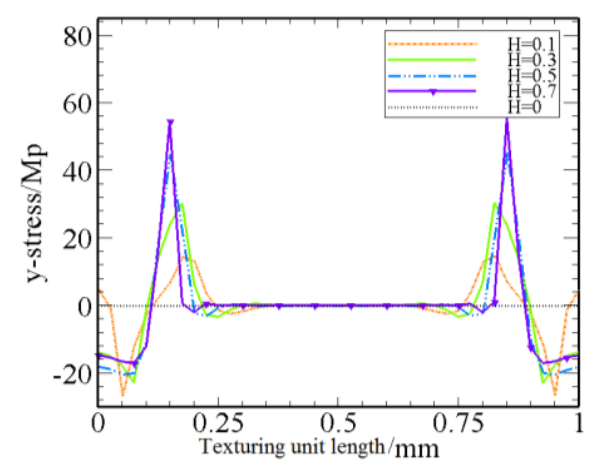

Figure 8. Distribution of stresses along the $y$-direction at different texturing depths.

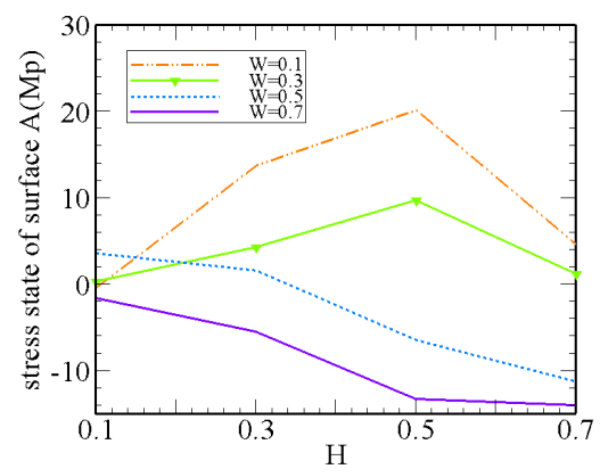

Figure 9. State of stress changes in texturing depth.

Therefore, the optimum design scale of texturing will be determined if only the $y$-direction is considered; the optimum sizes of texturing are $W=0.7$ and $H=0.7$. Under this size, surface texturing will automatically generate robust compressive stresses in the surface layer during rapid changes in temperature. Some processing methods [14], such as peen processing, also enhance the performance of components by strengthening the $y$-direction compressive stresses.

When the material surface performance is more sensitive to the $x$-direction stresses, the tensional stresses in the center region must be larger than those around it, or compressive stresses are formed. According to this analysis, the optimum texturing width is $W=0.1$ when considering the $x$-direction. Figure 10 shows the distribution of stresses along the $x$-direction at different texturing depths and when $W=0.1$. In the graph, when the texturing depth is $H=0.7$, the largest tensional stresses are in the center and the smallest tensional stresses around it will develop. Therefore, the optimum texturing depth is $H=0.7$ when considering the $x$-direction. In other words, the optimum design scale is $W=0.1$ and $H=0.7$ under these conditions. 


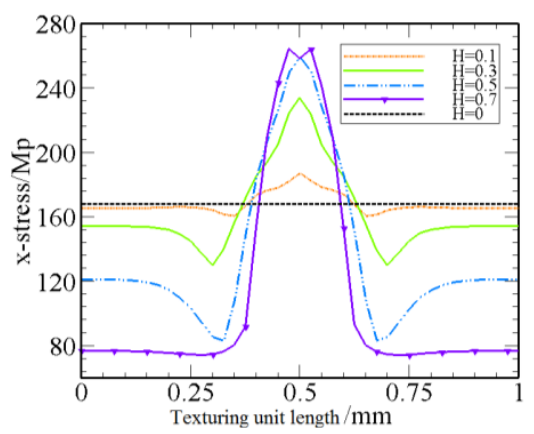

Figure 10. Distribution of stresses along the $x$-direction at different texturing depths and $W=0.1$.

When the stresses of both the $x$-direction and the $y$-direction are considered, the optimum texturing width is $W=0.5$. At this texturing width, the distribution of stresses along the $x$-direction under different texturing depths is as shown in Figure 11. When the texturing depth is $H=0.7$, the state of the $x$-direction stresses is most beneficial at $W=0.5$, and the state of the $y$-direction stresses can also achieve optimization, as shown in Figure 9. Thus, the optimum design scale parameters of texturing are $W=0.5$ and $H=0.7$ considering both the $x$-direction and the $y$-direction.

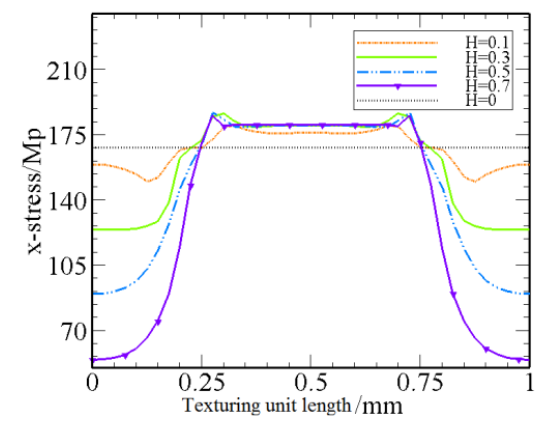

Figure 11. Distribution of stresses along the $x$-direction at different texturing depths and $W=0.5$.

\section{Conclusions}

Material surfaces sometimes experience rapid temperature changes, and the local surface will obviously generate thermal stresses, which may be detrimental to the material structure. In this study, a numerical approach was used to investigate the effects of surface texturing on stresses. Subsequently, the numerical simulation, based on FEM, was carried out, and the main conclusions are shown as follows:

(1) Surface texturing can automatically generate a beneficial stress distribution in a surface layer when a material experiences rapid temperature changes.

(2) There is an optimum design scale of texturing; the largest compressive stresses along the $y$-direction can be achieved when the texturing width and depth are $W=0.7$ and $H=0.7$, respectively.

(3) When the material surface performance is more sensitive to the stresses of the $x$-direction, the optimum texturing width is $W=0.1$ and the depth is $H=0.7$.

(4) When the material surface performance is more sensitive to the stresses of both the $x$-direction and the $y$-direction, the optimum texturing width is $W=0.5$ and the depth is $H=0.7$.

Acknowledgments: This work was supported by the National Basic Research Program of China (Grant No. 2010CB731703, 2012CB619505), the National Natural Science Foundation of China (Grant No. 51405520), and the Self-funding Research Program of the State key laboratory of high-performance complex manufacturing (Grant No. zzyjkt201308B). 
Author Contributions: All authors contributed equally to this article. Especially, Lei Han and Yunxin Wu established the numerical model and carried out the simulation about thermal stresses; Hai Gong and Wenze Shi managed the data information. All authors contributed to the writing of the paper.

Conflicts of Interest: The authors declare no conflict of interest.

\section{References}

1. Etsion, I.; Kligerman, Y.; Halperin, G. Analytical and experimental investigation of Laser-textured mechanical seal face. Tribol. Trans. 1999, 42, 511-516. [CrossRef]

2. Kovalchenko, A.; Ajayi, O.; Erdemir, A.; Fenske, G.; Etsion, I. The Effect of Laser Texturing of Steel Surfaces and Speed-Load Parameters on the Transition of Lubrication Regime from Boundary to Hydrodynamic. Tribol. Trans. 2004, 47, 299-307. [CrossRef]

3. Zhao, Y.; Han, L. CFD-based on research on the load-bearing capacity of asymmetric texture with different Reynolds number. Surf. Rev. Lett. 2013, 20, 1-7. [CrossRef]

4. Zhou, Y.; Zhu, H.; Tang, W.; Ma, C.; Zhang, W. Development of the theoretical model for the optimal design of surface texturing on cylinder liner. Tribol. Trans. 2012, 52, 1-6. [CrossRef]

5. Lu, P.; Wood, R.; Gee, M.; Wang, L.; Pfleging, W. The Friction Reducing Effect of Square-Shaped Surface Textures under Lubricated Line-Contacts-An Experimental Study. Lubricants 2016, 4, 1-13. [CrossRef]

6. Vandoni, L.; Demir, A.; Previtali, B.; Lecis, N.; Ugues, D. Wear Behavior of Fiber Laser Textured TiN Coatings in a Heavy Loaded Sliding Regime. Materials 2012, 5, 60-82. [CrossRef]

7. Ahmmed, K.; Grambow, C.; Kietzig, A. Fabrication of Micro/Nano Structures on Metals by Femtosecond Laser Micromachining. Micromachines 2014, 5, 19-53. [CrossRef]

8. Dumée, L.; She, F.; Duke, M.; Gray, S.; Hodgson, P.; Kong, L. Fabrication of Meso-Porous Sintered Metal Thin Films by Selective Etching of Silica Based Sacrificial Template. Nanomaterials 2014, 4, 86-99. [CrossRef]

9. Shen, C.; Khonsari, M. Tribological and Sealing Performance of Laser Pocketed Piston Rings in a Diesel Engine. Tribol. Lett. 2016, 64, 1-9. [CrossRef]

10. Usman, A.; Park, C. Optimizing the tribological performance of textured piston ring-liner contact for reduced frictional losses in SI engine: Warm operating conditions. Tribol. Int. 2016, 99, 24-36. [CrossRef]

11. Ighil, N.; Fillon, M. A numerical investigation of both thermal and texturing surface effects on the journal bearings static characteristics. Tribol. Trans. 2015, 90, 28-39.

12. Meng, F.; Zhang, L.; Liu, Y.; Li, T. Effect of compound dimple on tribological performances of journal bearing. Tribol. Int. 2015, 91, 99-110. [CrossRef]

13. Kishimoto, A.; Morita, M.; Asaoka, H.; Hayashi, H. Using ion exchange to control the mechanical strength of Naß-alumina ceramics. Solid State Ion. 2006, 177, 949-953. [CrossRef]

14. Wagner, L.; Mhaede, M.; Wollmann, M.; Altenberger, I.; Sano, Y. Surface layer properties and fatigue behavior in $\mathrm{Al}$ 7075-T73 and Ti-6Al-4V: Comparing results after laser peening; shot peening and ball-burnishing. Int. J. Struct. Integr. 2011, 2, 185-199. [CrossRef]

15. Ocana, J.L.; Correa, C.; García-Beltrán, A.; Porro, J.A.; Díaz, M.; Ruiz-de-Lara, L.; Peral, D. Laser Shock Processing of thin Al2024-T351 plates for induction of through-thickness compressive residual stresses fields. J. Mater. Process. Technol. 2015, 223, 8-15. [CrossRef]

16. Aydıner, C.C.; Ustundag, E. Residual stresses in a bulk metallic glass cylinder induced by thermal tempering. Mech. Mater. 2005, 37, 201-212. [CrossRef]

17. Hassani-Gangaraj, S.M.; Carboni, M.; Guagliano, M. Finite element approach toward an advanced understanding of deep rolling induced residual stresses, and an application to railway axles. Mater. Des. 2015, 83, 689-703. [CrossRef]

18. Zhang, X.; Li, H.; Duan, S.W.; Yu, X.; Feng, J.; Wang, B.; Huang, Z. Modeling of residual stress field induced in Ti-6Al-4V alloy plate by two sided laser shock processing. Surf. Coat. Technol. 2015, 280, 163-173. [CrossRef]

19. Aoki, S.; Nishimura, T.; Hiroi, T. Reduction method for residual stress of welded joint using random vibration. Nucl. Eng. Des. 2005, 235, 41-45. [CrossRef]

20. Lu, A.L.; Tang, F.; Luo, X.J.; Mei, J.F.; Fang, H.Z. Research on residual-stress reduction by strong pulsed magnetic treatment. J. Mater. Process. Technol. 1998, 74, 259-262. [CrossRef]

21. Jiang, W.; Zhang, Y.; Woo, W. Using heat sink technology to decrease residual stress in 316L stainless steel welding joint: Finite element simulation. Int. J. Press. Vessel. Pip. 2012, 92, 56-62. [CrossRef] 
22. Lu, L.; Sun, J.; Han, X.; Xiong, Q. Study on the Surface Integrity of a Thin-Walled Aluminum Alloy Structure after a Bilateral Slid Rolling Process. Metals 2016, 6, 1-12. [CrossRef]

23. Ma, D.; Mostafa, A.; Kevorkov, D.; Jedrzejowski, P.; Pugh, M.; Medraj, M. Water Impingement Erosion of Deep-Rolled Ti64. Metals 2015, 5, 63-86. [CrossRef]

24. Ramazani, A.; Mukherjee, K.; Abdurakhmanov, A.; Abbasi, M.; Prahl, U. Characterization of Microstructure and Mechanical Properties of Resistance Spot Welded DP600 Steel. Metals 2015, 5, 4-16. [CrossRef]

25. Yang, D.; Kim, Y.; Hur, M.; Lee, H.; Kim, Y.; Lim, T.; Kim, K.; Yang, S. Control of the Nano-Particle Weight Ratio in Stainless Steel Micro and Nano Powders by Radio Frequency Plasma Treatment. Metals 2015, 5, 58-69. [CrossRef]

26. Fichtner, T.; Wang, C.; Levin, A.; Kreiner, G.; Mejia, C.S.; Fabbrici, S.; Albertini, F.; Felser, C. Effects of Annealing on the Martensitic Transformation of Ni-Based Ferromagnetic Shape Memory Heusler Alloys and Nanoparticles. Metals 2015, 5, 484-503. [CrossRef]

27. Natxiondo, A.; Suárez, R.; Sertucha, J.; Larrañaga, P. Graphite and Solid Fraction Evolutions during Solidification of Nodular Cast Irons. Metals 2015, 5, 239-255. [CrossRef]

28. Zhou, W.; Zhang, R.; Ai, S.; Pei, Y.; Fang, D. Analytical modeling of thermal residual stresses and optimal design of $\mathrm{ZrO}_{2} /\left(\mathrm{ZrO}_{2}+\mathrm{Ni}\right)$ sandwich ceramics. Ceram. Int. 2015, 41, 8142-8148. [CrossRef]

29. Fialko, Y.; Sandwell, D.; Agnew, D.; Simons, M.; Shearer, P.; Minster, B. Deformation on Nearby Faults Induced by the 1999 Hector Mine Earthquake. Science 2002, 297, 1858-1862. [CrossRef] [PubMed]

30. Yang, X.; Zhu, J.; Nong, Z.; Lai, Z.; He, D. FEM simulation of quenching process in A357 aluminum alloy cylindrical bars and reduction of quench residual stress through cold stretching process. Comput. Mater. Sci. 2013, 69, 396-413. [CrossRef]

(C) 2016 by the authors; licensee MDPI, Basel, Switzerland. This article is an open access article distributed under the terms and conditions of the Creative Commons Attribution (CC-BY) license (http://creativecommons.org/licenses/by/4.0/). 